http://dx.doi.org/10.35381/racji.v5i8.577

\title{
Derecho a la defensa en la detención con fines investigativos
}

Right to defense in detention for investigative purposes

\author{
Gabriel Ismael Baculima-Llivisaca \\ gabriel.baculima@psg.ucacue.edu.ec \\ Universidad Católica de Cuenca, Cuenca \\ Ecuador \\ https://orcid.org/0000-0001-8315-1688 \\ Cecilia Ivonne Narváez-Zurita \\ inarvaez@ucacue.edu.ec \\ Universidad Católica de Cuenca, Cuenca \\ Ecuador \\ https://orcid.org/0000-0002-7437-9880 \\ Diego Fernando Trelles-Vicuña \\ dtrelles@ucacue.edu.ec \\ Universidad Católica de Cuenca, Cuenca \\ Ecuador \\ https://orcid.org/0000-0002-8466-7165 \\ Juan Carlos Erazo-Álvarez \\ jcerazo@ucacue.edu.ec \\ Universidad Católica de Cuenca, Cuenca \\ Ecuador \\ https://orcid.org/0000-0001-6480-2270
}

Recibido: 14 de noviembre de 2019

Aprobado: 17 de diciembre de 2019

\section{RESUMEN}

En el presente artículo se un análisis sobre la detención que regula una de las formas de privación de la libertad ambulatoria de una persona en Ecuador. Es común que esta detención se convierta en arbitraria, vulnera el debido proceso en su garantía al derecho a la defensa, por cuanto al investigado se le formula cargos en audiencia convocada dentro de las 24 horas de vigencia de la boleta de detención, vulnerando la posibilidad de contar con el tiempo y medios adecuados para su defensa. Por ello, el 
objetivo es analizar la vulneración al derecho a la defensa y evidenciar la realidad en el Ecuador. La metodología empleada para la edificación de la investigación, se basó en una tipología documental-bibliográfica. Se concluye que existe un vacío en la norma penal que permita asegurar la presencia de detenido con fines investigativos sin que causen vulneración a las garantías constitucionales.

Descriptores: Derechos fundamentales; Derecho a la defensa; Privación de libertad; Detención; Vulneración.

\begin{abstract}
In this article, we analyze the detention that regulates one of the forms of deprivation of ambulatory freedom of a person in Ecuador. It is common for this detention to become arbitrary, it violates the due process in its guarantee of the right to defense, since the investigated person charges him in a hearing convened within 24 hours of the validity of the detention slip, violating the possibility to have adequate time and means for their defense. Therefore, the objective is to analyze the violation of the right to defense and demonstrate the reality in Ecuador. The methodology used for the construction of the research was based on a documentary-bibliographic typology. It is concluded that there is a void in the criminal law that ensures the presence of detainees for investigative purposes without causing violation of constitutional guarantees.
\end{abstract}

Descriptors: Fundamental rights; Right to defense; Deprivation of freedom; Detention; Infringement.

\title{
INTRODUCCIÓN
}

La libertad de un ser humano presupone el elemento esencial para el desarrollo de los derechos fundamentales reconocidos en la Constitución de la República del Ecuador e instrumentos internacionales de derechos humanos, sobre la cual se construye la dignidad humana, la misma se encuentra recogida en el artículo 9 del Pacto Internacional de Derechos Civiles y Políticos (Asamblea General de las Naciones Unidas, 1966), así como en el artículo 7 de la Convención Americana de Derechos Humanos (Organización de Estado Americanos, 1969).

Al respecto, I constitución ecuatoriana en los arts. 76 y 77 garantiza a todas las personas que se encuentran sometidas a un procedimiento judicial, en donde se determine 
derechos y obligaciones de cualquier orden el respeto al debido proceso a través de las garantías constitucionales, antes de someterlas a una medida cautelar de privación de la libertad (Asamblea Constituyente de Montecristi, 2008), no obstante, en la legislación ecuatoriana existe un abuso del derecho cobijado por un manto de legalidad cuando se procede con la detención de un ciudadano con fines investigativos, detención que en ningún caso debería sobrepasar las 24 horas.

Situación que en la práctica diaria no se cumple, pues dentro de la vigencia de la boleta de detención la fiscalía solicita audiencia de formulación de cargos, notificando al detenido con la respectiva convocatoria sin cumplir el plazo de 72 horas mínimas antes de la audiencia respectiva como lo dispone el art. 575 del Código Orgánico Integral Penal, dejando al procesado en indefensión y vulnerando el derecho a la defensa a no tener el tiempo necesario para realizar una defensa adecuada, en este sentido, queda en evidencia la vulneración al debido proceso (Guzmán Chávez, 2019).

Es por eso, que en todo proceso penal la Constitución de la República del Ecuador al referirse a las personas privadas de libertad, en su art. 77 núm. 1, determina que la privación de libertad no será la regla general prefiriendo otros medios alternativos para garantizar la presencia del acusado a todas las etapas procesales (Ibídem).

Ahora bien, una detención exceptuándose el delito flagrante, requiere como regla imprescindible orden escrita del juez competente y tiene una duración de 24 horas desde su captura, para tal efecto, se aplicará de conformidad con los casos, plazos, condiciones y requisitos de la ley, respetando el cumplimiento de la seguridad jurídica como aquella que contiene "normas previas claras públicas y aplicables por las autoridades competentes" (Asamblea Constituyente de Montecristi, 2008, pág. 54). Normas que anteponen la libertad a la privación de la misma, como un principio o mandato de optimización que ordena el cumplimiento de su contenido en la mayor medida posible, por lo que su inobservancia refleja la vulneración a la norma constitucional.

Atendiendo estas consideraciones, se pretende demostrar la real vulneración del 
derecho a la defensa de los procesados en el Ecuador, cuando su detención obedece a una orden judicial con finalidad investigativa. El problema radica en impedir a las personas detenidas con fines investigativos, contar con el tiempo y medios idóneos para ejercer una defensa técnica eficaz, como lo consagra la Constitución de la República del Ecuador, cuando se pretende formular cargos sin contar con el debido tiempo de notificación para ejercer su defensa. En este contexto, el objetivo de la presente investigación consiste en analizar el derecho a la defensa en la detención con fines investigativos como mecanismo de prevención de la vulneración del tiempo y medios idóneos para ejercer una defensa técnica y eficaz (Masabanda Analuiza, Aman Llerena, Montero Solano \& Javier Analuiza, 2019).

\section{DESARROLLO}

\section{El derecho a la defensa como norma constitucional}

Desde el 20 de octubre del año 2008, en Ecuador entró en vigencia una nueva constitución, que formar parte del denominado neoconstitucionalismo, donde se encuentran consagrados principios, derechos y garantías fundamentales, sin embargo, se le considera como sistema intrínsecamente incoherente e incompleto, por cuanto la razón humana no es capaz de proporcionar todas las formas en las que se pueden vulnerar derechos y peor aun únicamente positivizar todas las condiciones $y$ obligaciones emanadas de los derechos, puesto que son vastas (Avila, 2011). A este respecto, la Asamblea Constituyente de Montecristi (2008) reconoce a la República ecuatoriana como un "Estado constitucional de derechos y justicia social" (p.19), al mismo tiempo determina como eje central de la constitución y el más alto deber del Estado, la protección y respeto de los derechos, que para tal efecto son inalienables, irrenunciables, indivisibles, independientes y de igual jerarquía.

Dentro de este marco, como garantía básica de un Estado constitucional, se centran dos temas fundamentales, el primero es, el debido proceso en la garantía del derecho a la defensa consagrada en el art 76 núm. 7 de la Constitución del Ecuador (Asamblea 
Constituyente de Montecristi, 2008), esta situación, desemboca en el segundo tema que es la vulneración del derecho a la defensa, que hace referencia a cuando con fines investigativos se procede con la detención del investigado y esta detención excede el tiempo permitido de 24 horas conforme el art. 532 del Código Orgánico Integral Penal (Asamblea Nacional,COIP, 2014), con la finalidad de formular cargos sin el debido respeto a los plazos necesario para el ejercicio a la defensa.

En este sentido, se comprende el derecho a la defensa como aquel que se encuentra en íntima relación con la propia condición humana (Lavina, Steluta, y Danil, s/f), y como garantía constitucional al debido proceso. El Estado ecuatoriano desarrolla el derecho a la defensa en el art. 76 numeral 7 de la Constitución de la República del Ecuador, en cuanto, se reconoce en todo proceso donde se traben Litis, en el que determinaren derechos y obligaciones como el derecho al debido proceso incluido como garantía básica al derecho a la defensa en donde nadie podrá ser privado de esta garantía en ninguna etapa o grado del procedimiento (Asamblea Constituyente de Montecristi, 2008, pág. 50).

En virtud de las garantías básicas, contrario a la acusación se reconoce a la persona investigada, acusada o procesada de un acto típico y antijurídico el derecho a la defensa, en todas sus etapas procesales desde su investigación hasta la etapa de juicio de ser el caso, siendo este un proceso dispositivo basado en el principio de contradicción tanto en su vertiente material como en el desarrollo adecuado de sus defensa (Gomez , 2008). En consecuencia, la legitima contradicción es la base regulatoria de las todas relaciones sociales y es la mayor expresión del respeto a la garantía constitucional y legal a la defensa, siendo irrenunciable e inalienable, es en ese momento donde se garantiza el debido respeto a los derechos fundamentales y su igualdad jerárquica (Hernández, 2013). En síntesis, el derecho a la defensa es un derecho fundamental que permite hacer frente a un proceso penal en igualdad de condiciones, el mismo que asiste a todas las personas mediante el ejercicio de la defensa, entre otras garantías a ser asistido por un profesional del derecho 
permitiéndoles oponerse eficazmente las pretensiones punitivas (Oré, s/f).

De lo antes expuesto, se conceptualiza a la defensa procesal como un verdadero derecho, que tiene un nexo formal y material con el debido proceso como garantía fundamental, que se presenta en todos las actuaciones procesales e incluso en los diferentes azares de la vida, permitiendo un trato en igualdad de condiciones, contando con el tiempo necesario para forjar su defensa y exponerla ante autoridad competente, esto constituye un verdadero y justo proceso constitucional (Hernández, 2013). En este marco de análisis, Salazar y Montero (s/f) concluyen que el derecho a la defensa es la garantía del debido proceso por excelencia como un ejercicio efectivo de las garantías de una persona procesada.

A lo largo de la historia, en la edad media donde no exista presunción de inocencia sino presunción de culpabilidad, se construyó la obra denominada Dei Delitti e Delle Pene del jurista Cesare Beccaria, donde se abogó por el principio de legalidad y el derecho a la defensa por el año 1764. A partir de ello, se formaliza por primera vez en la declaración de los derechos del Estado de Virginia en el año de 1776, posterior en la enmiendas V y VI de la Constitución de Estados Unidos, siguiendo su construcción en la Declaración de Derechos del Hombre y del Ciudadano en el año 1789, sin embargo, fue en la Constitución francesa de 1793 donde se dispuso que, nadie puede ser juzgado y castigado sino después de haber sido oído o legalmente llamado (Matyas, 2013, págs. 137,138).

Así mismo, en el ámbito internacional el derecho a tener una defensa adecuada, justa y oportuna, fue el resultado de las dos post guerras mundiales, donde se violentaron los más elementales derechos como la dignidad e igualdad, en efecto, se suscribe la carta de las Naciones Unidas que dio origen a la Corte Internacional de Justicia como un órgano judicial (Carta de las Naciones Unidas, 1945).

De igual manera, en el Pacto Internacional de Derechos Civiles y Políticos, para que los seres humanos gocen de los derechos consagrados en tratado internacional mencionado, se crean condiciones para su adecuado ejercicio como aquel que consta 
en el at 14 núm. 3 lit. d. disponiendo que toda persona tiene derecho de estar presente en el proceso, así como gozar de una asesoría legal de su elección o nombrarle un abogado de oficio de manera gratuita, en respeto del derecho a la defensa (Asamblea General de las Naciones Unidas, 1966), dentro de este marco, el art 8 núm. 2 de la Convención Americana sobre Derechos Humanos, reconoce a todas las personas inmersas en la materialidad y responsabilidad de delitos, el derecho a la presunción del estado de inocencia y el derecho del inculpado de defenderse personalmente o de ser asistido por un defensor (Organización de Estado Americanos, 1969).

En consecuencia, se evidencia el avance histórico del derecho a la defensa, de un sistema inquisitivo vulnerador de todo derecho o garantía a uno garantista de los derechos fundamentales de los seres humanos, sistema inquisitivo que brindaba las facultades de pesquisa y juzgamiento a una misma persona, el juzgador (Gonzalez P, 2011, pág. 5). Por otra parte, un sistema dispositivo es aquel que, cuando las partes procesales acusador (Fiscalía) y defensa (acusado) son adversarios en el sistema penal, quienes se enfrentan en igualdad de condiciones, desarrollan pruebas y sus respectivos argumentos en frente de un Juez imparcial, quien decidirá en base de lo alegado y debidamente justificado, garantizando la defensa en todas sus etapas (González, 2011).

Se considera un avance histórico en materia de derecho a la defensa, desde un sistema que violentaba el debido proceso coartando el principio de contradicción, a un sistema dispositivo que se basa en principios como: mínima intervención penal, favorabilidad y garantizando el estatus de inocencia, logrando el pleno desarrollo del derecho a la defensa como garantía al debido proceso, como derechos fundamentales y por consiguiente respetando la supremacía de la constitución. Al respecto, Ramírez,(2014) refiere que el Estado constitucional desplazó al Estado legalista decimonónico donde primaba y era superior la ley ordinaria, considerada incluso como fuente de derecho y en donde los jueces realizaban análisis mecánicos muy arbitrarios, fundamentados en la supremacía de la norma infra constitucional violentando los derechos fundamentales 
de las personas.

De tal forma que, un Estado constitucional como el ecuatoriano, desarrolla un nuevo modelo de organización jurídico y político, prima facie garantista de los principios y derechos fundamentales, presentado un cambio de paradigma de Estado legalista a un Estado constitucional de derechos y justicia social, fundado en la supremacía de la constitución como norma suprema (Granda Torres \& Herrera Abrahan, 2019). En este orden de ideas, Ferrajoli (2006) considera, que del derecho no solo se positiviza su ser, sino principalmente su deber ser, sus condiciones de validez el motivo de su existecia, que no es otro que el pleno desarrollo de los prinicipios y los derechos fundamentales.

Así mismo, un Estado constitucional reconoce y garantiza a los derechos no solo desde su aspecto y estudio ontológico, sino también desde su aspecto deontológico, convirtiendo al Estado y a la norma en garantes de los derechos fundamentales, teniendo por objeto el amparo directo y eficaz de los derechos reconocidos en la Constitución del Ecuador, con la finalidad de asegurar el cumplimento de los derechos y su eventual reparación, por abuso del más fuerte, como por ejemplo el derecho de proteger la vida contra quien es más fuerte físicamente (Ferrajoli, 2006).

Por su parte el derecho a la defensa como norma de derecho fundamental, es asumido por Alexy (como se citó en Bernal, 2008) como el derecho fundamental con carácter de regla o con carácter de principio. La regla es de cumplimiento obligatorio ya que es norma y como principio se lo entiende como mandatos de optimización, que ordena la realización de su contenido en la mayor medida posible, en relación con los medios jurídicos y fácticos. En el cuadro 1 se presenta la diferencia entre regla y principio:

\section{Cuadro 1}

Diferencia entre regla y principio

\begin{tabular}{ll}
\hline Regla & Principio \\
\hline Normas a realizarse en la mayor medida & Mandatos de optimización, su cumplimiento \\
posible, dentro de las posibilidades jurídicas & es en diferente grado y dependen no solo de \\
y reales existentes. & las posibilidades reales sino jurídicas. \\
Contienen mandatos definitivos & Contiene mandatos prima facie \\
Ejm. Derecho a la Vida, derecho a la defensa & Ejm. derecho a la Vivienda \\
\hline
\end{tabular}

Cuadro creada a partir de Alexy (como se citó en Bernal, 2008). 
Desde la perspectiva más general, los derechos fundamentales son aquellos inherentes al ser humano, van de la mano del desarrollo mundial y crecimiento económico que no es estático es evolutivo a las nuevas necesidades del ser humano, por lo que el derecho a la defensa emerge como fuente de protección a los principios y reglas del más débil contra el abuso del más fuerte, Por lo expuesto, sin duda alguna el derecho a la defensa constituye un imperativo ineludible para el desarrollo del constitucionalismo fundado en el respeto y protección de los derechos fundamentales de los ciudadanos (Ferrajoli, 2006) .

\section{La detención como acto vulnerador de derechos}

La detención, es una medida cautelar personal consistente en la privación fáctica temporal del derecho a la libertad ambulatoria, ordenada por una autoridad competente en contra de una persona sobre quien existe la sospecha de responsabilidad de un acto ilícito típico y antijurídico, dentro de un máximo de tiempo (Pizarro, 2010). En esta perspectiva, con el término detención, se entiende la privación de libertad sobre un individuo en el desarrollo de un proceso penal o sin el desarrollo del mismo, obstaculizando su libertad de transito (Falcone, 2012, pág. s/p).

Por consiguiente, la detención es el acto de hecho más que de derecho sobre la cual existe un manto de legalidad con el cual se priva de la libertad a una persona contra quien existe sospecha del cometimiento de una acto antijurídico para ponerle a las órdenes de autoridad competente por un tiempo máximo establecido, con la finalidad de determinar la responsabilidad de un acto ilícito (Pizarro, 2010), de hecho, solo cuando la libertad es inherente a la persona y ésta no tiene limitaciones externas existe un verdadero respeto a los derechos fundamentales, considerando a la libertad como la piedra capital del constitucionalismo contemporáneo (Haberle, 1997).

En virtud de lo expuesto, se considera a la detención como un acto contrario a la libertad impropio a todo ser humano sin distinción alguna, es por eso que, la Asamblea Constituyente de Montecristi (2008), reconoce el derecho de libertad en la Constitución 
de la República del Ecuador art. 66 puntualizado en los 4 literales del núm. 29 (p.46), igualmente, el art. 77 núm. 1, del mismo texto fundamental, considera la privación de la libertad como un acto que no es regla general (p.51), este artículo fue reformado mediante consulta popular y referéndum publicado el en el R.O 490,13-VIII-2011 (Consejo Nacional Electoral, 2011), en donde la detención abandona el carácter de excepcional a no ser la regla general, es decir, no es de carácter obligatorio. Las reflexiones anteriores, se corresponden con la libertad ambulatoria, que es gozada por todas las personas sin excepción alguna, la misma que se ve reprimida solo cuando existe orden escrita de Juez competente exceptuándose esta orden cuando se trate de un delito flagrante donde cualquier persona puede proceder con la aprensión y ponerle a órdenes de la policía nacional (Vaca, s/f).

La privación de libertad es una medida cautelar regulada en la legislación ecuatoriana como mecanismo excepcional dentro de un proceso penal, que garantiza la presencia del sospechoso a las etapas procesales, así como el cumplimiento de una pena y la reparación integral a la víctima (Asamblea Nacional,COIP, 2014, pág. 615). A este respecto, la Asamblea Nacional (COIP, 2014) regula la privación de la libertad de una persona que aún no cuenta con sentencia en firme de diferentes formas como; aprensión, detención, prisión preventiva.

En virtud de lo expuesto, la aprensión se podría interpretar como un deber moral que permite a cualquier persona proceder a privar de la libertad al individuo sorprendido en delito flagrante, quien deberá ponerlo inmediatamente a las órdenes de la Policía Nacional, la misma se encuentra consagrada en el art 526 del Código Orgánico Integral Penal, ahora bien, en cuanto a la Detención, para Cabanellas (2005, pág. 128) es la privación de libertad o arresto provisional, la misma que es ordenada por autoridad competente y por un tiempo determinado, regulada en el art. 530 del Código Orgánico Integral Penal, por último, la prisión preventiva, es el acto legal que coarta la libertad de tránsito, otorgada dentro del marco jurisdiccional competente y es solicitada por Fiscalía General del Estado, con el fin de garantizar la comparecencia de la persona procesada 
a las etapas del juicio, petición que debe ser motivada y está regula en el art 534 del Código Orgánico Integral Penal (Asamblea Nacional,COIP, 2014).

En relación a la problemática expuesta, la detención con fines investigativos, en la legislación penal ecuatoriana como ya se mencionó en líneas anteriores, está regulada en el art 530 del Código Orgánico Integral Penal y debe cumplir requisitos para su efectiva validez, consagrados en el art. 531 del mimos cuerpo legal, se trata de, la motivación, lugar y la fecha en que se expide la detención y debe contener firma de la o el juzgador competente (Asamblea Nacional,COIP, 2014, pág. 614), detención que tiene una duración de 24 horas y únicamente para el fin investigativo solicitado y para garantizar la integridad del investigado, precautelando el estado de inocencia del mismo, en este contexto, la fase de investigación previa de acuerdo al artículo 472 núm. 3 y 584 del Código Orgánico Integral Penal es estrictamente reservada, teniendo como elemento transversal, el derecho a la defensa (Asamblea Nacional,COIP, 2014). Uno de los componentes más importantes que se encuentra en armonía al respeto del debido proceso en la garantía del derecho a la defensa y que protege al individuo investigado frente a poder punitivo estatal, lo regula el artículo 575 núm. 1 del Código Orgánico Integral Penal, que garantiza, contar con el tiempo de al menos setenta y dos horas desde la notificación hasta la celebración de una audiencia, tiempo suficiente para la preparación de la defensa, salvo en los casos de delitos flagrantes (Asamblea Nacional,COIP, 2014, pág. 632), por consiguiente, es en este momento donde se violenta el derecho a la defensa cuando se irrespeta el tiempo necesario para el desarrollo de una audiencia de formulación de cargos, instalando la misma, durante la vigencia de la detención con fines investigativos.

Al respecto, la Corte Interamericana de Derechos Humanos (Corte IDH) en el Caso Barreto Leiva Vs. Venezuela, ha establecido que en el momento que se impide, el pleno ejercicio del derecho de defensa de los ciudadanos se potencia el poder investigativo del Estado, provocando desproporción en la igualdad de condiciones y un desmedro en el pleno ejercicio de los derechos fundamentales del individuo investigado (Caso 
Barreto Leiva Vs. Venezuela, 2009, pág. 9), este estándar de aplicación del derecho a la defensa, de acuerdo a la misma Corte Interamericana de Derechos Humanos debe imperiosamente poder ejercerse en todo momento desde la existencia de una posible responsabilidad penal de un hecho punible y sólo termina cuando finaliza el proceso (Caso Ruano Torres Y Otros Vs. El Salvador, 2015, p. 45).

Por consiguiente, en el marco de protección de derecho fundamental la detención con fines investigativos, a pesar que la misma es legal pues existe en el ordenamiento normativo, esta se contrapone al derecho a la libertad considerado como derecho fundamental reconocido tanto en los tratados internacionales así como en la Constitución ecuatoriana, siendo la base sobre la cual se desarrolla todas las garantías constitucionales, de tal manera que al privarle a una persona del derecho a la libertad ambulatoria se tiene que poner a las órdenes de autoridad competente y será retenido únicamente por el tiempo requerido y puesto en libertad inmediatamente cumplido los propósitos de su detención, para así garantizar el respeto al debido proceso.

Para demostrar la situación expuesta, en loa cuadros 2 y 3 mediante el análisis de dos casos concretos extraídos del sistema SATJE de la Función Judicial, se demuestra que la convocatoria a la audiencia de formulación de cargos es ordenada dentro de la vigencia de la detención con fines investigativos, en donde, a más de ser un acto vulnerador del derecho a la defensa, impidiendo contar con el tiempo necesario para ejercer una defensa adecuada, en los dos casos se dictan medidas cautelares de prisión preventiva, destruyendo la presunción de inocencia que es un estado inherente al ser humano, estado que es considerado como la otra orilla del ejercicio sancionador y arbitrario del Estado ecuatoriano, en consecuencia, para que se aplique la detención se exige un criterio de estricta necesidad e indispensabilidad arribada tras un estricto juicio de proporcionalidad, razonabilidad, idoneidad y necesidad (Sorza, S/F). 


\section{Cuadro 2}

Análisis de caso 1

$\begin{array}{cccccc}\begin{array}{c}\text { Indagación } \\ \text { previa número: }\end{array} & \begin{array}{c}\text { Nombre del } \\ \text { investigado: }\end{array} & \begin{array}{c}\text { Autoridad } \\ \text { solicitante: }\end{array} & \begin{array}{c}\text { Autoridad } \\ \text { competente: }\end{array} & \begin{array}{c}\text { Fecha } \\ \text { de }\end{array} & \begin{array}{c}\text { Fecha de } \\ \text { detención: }\end{array} \\ 090301817120048 & \text { Elías } & \text { Fiscal del } & \text { Juez del } & \text { emisión } & 14 \text { de mayo } \\ & \text { Agustín Q. } & \text { cantón } & \text { Cantón } & \text { de la } & \text { de } 2018 \text { a } \\ & \text { Ch. } & \text { Balao } & \text { Naranjal. } & \text { boleta: } & \text { las 19h15 } \\ & & \text { Kenneth A. } & & 09 \text { de } & \\ & & & & \text { febrero } & \\ & & & & \text { de 2018 }\end{array}$

\section{Antecedentes}

Se solicita boleta de detención con fines de investigación contra Elías Agustín Q. Ch. por no haberse presentado a rendir versión en la indagación previa 090301817120048, de la detención se presenta acción de Habeas Corpus con número 09113-2018-00023 la misma que es rechazada por la sala citando la sentencia 237-15-SEP-CC del caso 1530-12-EP. (Accion de Habeas Corpus, 2018).

\section{Acto vulnerador del derecho a la defensa}

El día 15 de mayo del 2018 14h20, el requerido rindió su versión en la Fiscalía de Garantías y Personas 1 del Cantón Balao ante el Fiscal, pero en lugar de ponerlo en libertad, luego de receptar su versión el Fiscal solicita al Juez Audiencia de Formulación de Cargos y el Juez ese mismo día a las 16h45 acepta la petición del fiscalía, lo notifica en la casilla 9999 y correo electrónico miltonlupe@hotmail.com y señala audiencia para el mismo día 15 de mayo de 2018 a las 17h10, sin considerar lo que dispone el art. 575 núm. 1 del COIP, que establece que se notificara al menos 72 horas de anticipación a las partes cuando no se trate de flagrancia. Y el juez a petición de fiscalía que formuló cargos, dicta la medida de prisión preventiva en contra de Elías Agustín Q. Ch. La 
defensa considera que se ha violentado los principios que consagra la constitución, art. 76, núm. 7, lit., a y b, art 575 del COIP, numeral 1, art. 594 núm. 2 ibidem, en armonía con art. 45 numeral 2 literal d, de la Ley Orgánica de Garantías Jurisdiccionales y Control Constitucional

\section{Cuadro 3}

Análisis de caso 2

$\begin{array}{ccclcc}\begin{array}{c}\text { Investigación } \\ \text { previa número }\end{array} & \begin{array}{c}\text { Nombre del } \\ \text { investigado }\end{array} & \begin{array}{c}\text { Autoridad } \\ \text { solicitante }\end{array} & \begin{array}{l}\text { Autoridad } \\ \text { competente }\end{array} & \begin{array}{c}\text { Fecha } \\ \text { de }\end{array} & \begin{array}{c}\text { Fecha y } \\ \text { lugar de }\end{array} \\ 010801817250017 & \text { Guido } & \text { Fiscal del } & \text { Jueza del } & \text { emisión } & \text { detención } \\ & \text { G.O.A. } & \text { cantón } & \text { Cantón } & \text { de la } & 24 \text { de junio } \\ & & \text { Santa } & \text { Santa Isabel. } & \text { boleta } & \text { de 2017, } \\ & & \text { Isabel. } & & 23 \text { de } & \text { Cantón } \\ & & & \text { junio de } & \text { Santa Isabel } \\ & & & & & \\ & & & & \end{array}$

\section{Antecedentes}

Se solicita detención con fines investigativos en contra de Guido G.O.A. por el cometimiento de un supuesto delito de captación ilegal de dinero. Art 323 COIP.

\section{Acto vulnerador del derecho a la defensa}

El día 24 de junio de 2017, el requerido rindió su versión en la Fiscalía del Cantón Santa Isabel, pero en lugar de ponerlo en libertad, luego de receptar su versión la Fiscal solicita a la Jueza Audiencia de Formulación de Cargos y la Jueza convoca al desarrollo de audiencia de formulación de cargos a desarrollar ese mismo día 24 de Junio de 2017 a las $12 \mathrm{~h} 41$ en donde a más de otras medidas cautelares se dispone la prisión preventiva.

Fuente: casos obtenidas del sistema SATJE de la Funcion Judicial. 


\section{METODOLOGÍA}

El presente artículo se desarrolló en el marco de la investigación jurídica empírica, puesto que se buscó un acercamiento entre el sistema normativo ecuatoriano y la realidad social que actualmente atraviesa el país, para ello se utilizaron los métodos analítico-sintético, inductivo-deductivo, histórico-lógico y teórico, los mismos que permitieron plantear el problema, fundamentar teóricamente las variables de estudio y buscar una solución al conflicto expuesto. La técnica de investigación jurídica posibilitó el conocimiento a profundidad del saber empírico - técnico del derecho a la defensa en la detención con fines investigativos.

La recolección de información se hizo a partir de la revisión documental (documentos jurídicos, leyes, códigos, libros, artículos científicos), proceso que posibilitó el análisis e interpretación de la información y datos revisados. Finalmente, la investigación logro un alcance descriptivo - explicativo ya que al inicio se expuso las características del problema, se determinaron las causas jurídico - sociales que lo provocan, así como los escenarios y las condiciones en que se vulnera el derecho a la defensa de los procesados en Ecuador (González, Narváez y Erazo, 2019).

\section{APORTES}

El derecho a la defensa es un derecho inherente al ser humano, es la garantía fundamental sobre el cual se constituye el debido proceso, el mismo que otorga validez a todo acto jurisdiccional, garantizando el cumplimiento de las solemnidades sustanciales necesarias que permitan contradecir, refutar y aportar al esclarecimiento de un hecho y la declaración de la verdad en igualdad de condiciones.

El derecho a la defensa, es reconocido no solo en la normativa interna de un país sino es la garantía consagrada en cada uno de los tratados internacionales sobre derecho humanos, por lo que aplicando el bloque de constitucionalidad, en Ecuador es la base de toda la normativa vigente, que garantiza al procesado gozar de la representación técnica de un profesional del derecho, así mismo, contar con el tiempo necesario para 
sustentar una defensa adecuada y en efecto, desarrollar los medios probatorios más idóneos con el fin de mantener su estado de inocencia.

Por consiguiente, al ser la libertad ambulatoria un derecho inherente al ser humano, la detención con fines investigativos vulnera el debido proceso, cuando se la realiza sin observar los requisitos materiales y formales especialmente el relacionado con la temporalidad excediéndose de las 24 horas de duración la detención y desvirtuándose su finalidad única y exclusiva de investigación.

Sobre las bases de las ideas expuestas, resulta claro que la detención con fines investigativos, es un rezago de un Estado inquisitivo de derecho donde se puede privar la libertad de tránsito, con la sola existencia de una presunción o sospecha de responsabilidad, violentando el bien jurídico más anhelado por la humanidad, la libertad. La detención con fines investigativos sin el debido respeto a su finalidad, que es la investigación, es una clara vulneración al debido proceso y de la misma manera al formular cargos dentro de las 24 horas de vigencia de la boleta de detención con fines investigativos se evidencia la vulneración a la garantía del derecho a la defensa.

Como resultado del análisis realizado y al observarse que el Estado a través d-e Fiscalía es quien ostenta el monopolio de la acción penal pública y tiene la obligación de investigar y sancionar la antijuricidad de los actos, para lo cual necesita garantizar la presencia del investigado al proceso, sin duda, es necesario una reforma al art 530 del COIP, para tal efecto se propone, como medida no vulneradora al derecho a la defensa, en apego estricto del art 76.7 y 77.1 de la Constitución de la República del Ecuador la continuidad de la detención hasta por setenta y dos horas a la instalación de audiencia de formulación de cargos, siempre que concurran los siguientes elementos: que exista posibilidad real de fuga del investigado, la renuencia reiterada a la comparecencia voluntaria, que se trate de delitos sancionados con reclusión y que el acto delictivo cause grave conmoción social, garantizando de tal manera el tiempo suficiente para contar con los medios adecuados y ejercer una defensa técnica en respeto de los derechos fundamentales del procesado. Tal como se presenta en la figura 1. 


\section{Derecho a la defensa en la detención con fines investigativos}

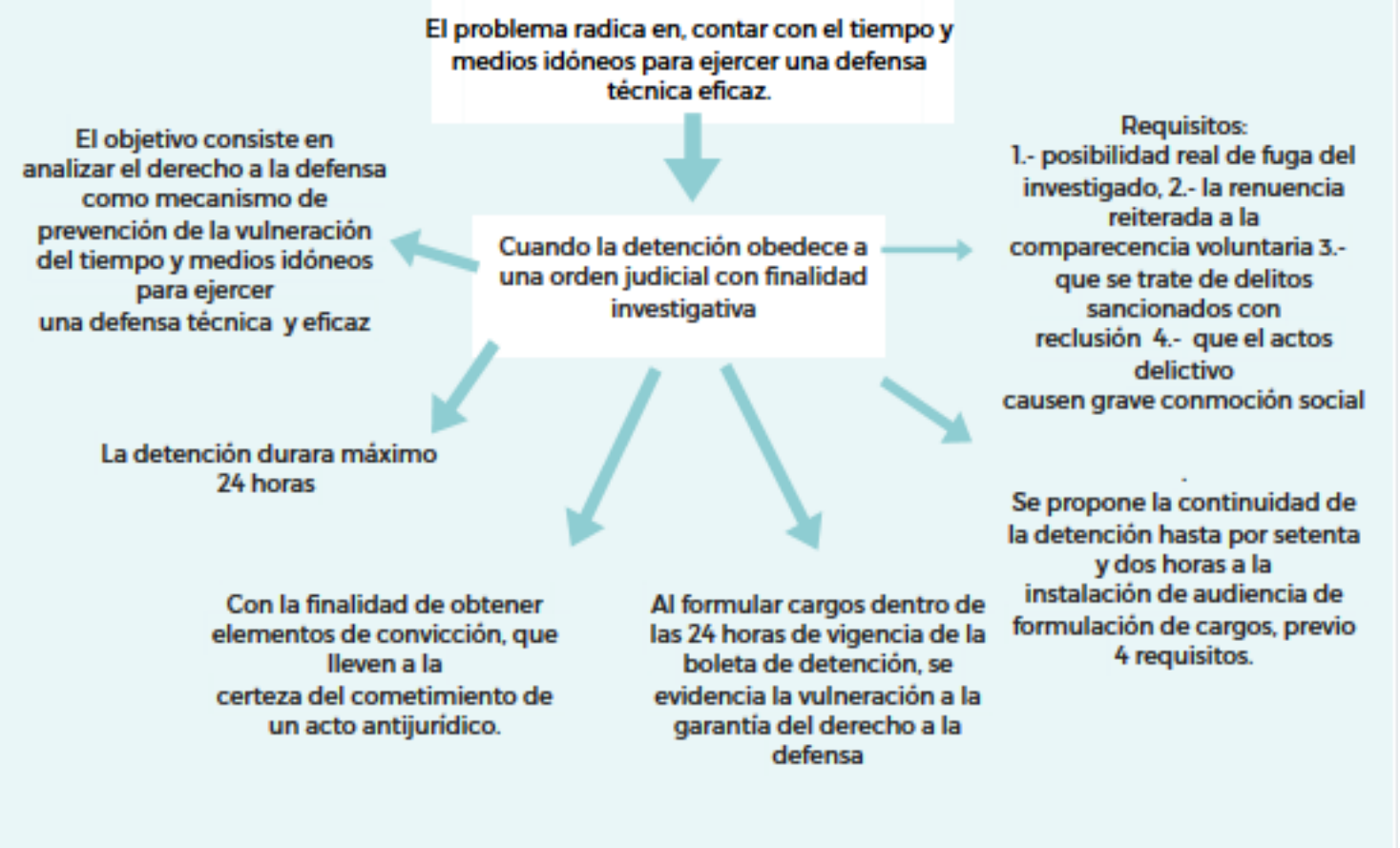

Figura 1. Derecho a la defensa en la detención con fines investigativos

\section{REFERENCIAS CONSULTADAS}

1. Accion de Habeas Corpus, 09113-2018-00023 (04 de Junio de 2018).

2. Alexy, R. (2008). Teroría de los derechos fundamentales. Madrid: Centro de estudios políticos y constitucionales.

3. Asamblea Constituyente de Montecristi. (2008). Constitución dela República del Ecuador. Alfaro: Ediciones Legales.

4. Asamblea General de las Naciones Unidas. (16 de Diciembre de 1966). Pacto Internacional de Derechos Civiles y Políticos. Nueva York, Estados Unidos. Obtenido de https://www.ohchr.org/Documents/Professionallnterest/ccpr_SP.pdf

5. Asamblea Nacional,COIP. (2014). Codigo Organico Integla Penal. Quito. 
6. Avila, R. (2011). El neoconstitucionalismo transformador. Quito, Ecuador: Ediciones Abya-Yala. Recuperado el Diciembre de 2019

7. Bernal, C. (2008). Teoría de los derechos fundamentales. Madrid.

8. Cabanellas, G. (2005). Diccionario Jurídico Elemental. Heliasta S.R.L.

9. Carta de las Naciones Unidas. (1945). Carta de las Naciones Unidas. San Francisco.

10. Caso Barreto Leiva Vs. Venezuela, 11.663 (Corte Interamericana de Derechos Humanos 17 de Nov. de 2009). Obtenido de http://www.corteidh.or.cr/docs/casos/articulos/seriec_206_esp1.pdf

11. Caso Ruano Torres Y Otros Vs. El Salvador (Corte Interamericana de Derechos Humanos 05 de Oct. de 2015). Obtenido de http://www.corteidh.or.cr/docs/casos/articulos/seriec_303_esp.pdf

12. Consejo Nacional Electoral. (13 de Julio de 2011). Registro Oficial. Resultados del referéndum y consulta popular 2011. Quito, Pichincha, Ecuador. Obtenido de www.registroficial.gob.ec

13. Falcone, D. (2012). Concepto y sistematización de la detención ilegal en el proceso penal chileno. Revista de Derecho de la Pontificia Universidad Católica de Valparaíso. Obtenido de https://scielo.conicyt.cl/scielo.php?script=sci_arttext\&pid=S071868512012000100011

14. Ferrajoli, L. (15 de julio de 2006). Sobre los derechos fundamentales. Cuestiones Cosntitucionales, $114 . \quad$ Obtenido de http://www.scielo.org.mx/pdf/cconst/n15/1405-9193-cconst-15-113.pdf

15. Gomez , J. (2008). El sistema de enjuiciamiento criminal propio de un estado de derecho. Mexico D.F.: Intituto Nacional de Ciencias Penales. Obtenido de https://books.google.com.ec/books?id=KS2kGqM0gpQC\&printsec=frontcover\&hl $=$ es\#v=onepage $\& q=\% 20$ principal\%20derecho\%20del\%20acusado\%20es\%20el\% $20 \mathrm{de} \% 20$ defensa\&f $=$ false

16. González Andrade, L. F., Narváez Zurita, C. I., \& Erazo Álvarez, J. C. (2019). La auditoría gubernamental y su incidencia en la gestión institucional y manejo de recursos públicos. Cienciamatria, 495.

17. Gonzalez P, H. J. (Diciembre de 2011). eumed.net. Obtenido de http://www.eumed.net/rev/cccss/16/midgt.pdf 
18. Guzmán Chávez, M. (2019). El principio constitucional de la tutela judicial efectiva vulnerado por la acción de nulidad de sentencias. IUSTITIA SOCIALIS, 4(7), 135-145. doi:http://dx.doi.org/10.35381/racji.v4i7.366

19. Granda Torres, G., \& Herrera Abrahan, C. (2019). Análisis de los tipos penales y su importancia para determinar responsabilidad penal. IUSTITIA SOCIALIS, 4(7), 220-232. doi:http://dx.doi.org/10.35381/racji.v4i7.443

20. Haberle, P. (1997). La Libertad Fundamental en el Estado Constitucional. Peru. Obtenido https://books.google.com.ec/books?hl=es\&lr=\&id=suuJUJ1eKI0C\&oi=fnd\&pg=PA $11 \& d q=+$ La+Libertad+Fundamental+en+el+Estado+Constitucional\&ots=5Ht7yR4 OGB\&sig=M9m98m_8t2EqlJ4bj8yvagQnPz4\&redir_esc=y\#v=onepage\&q=la\%20 pieza\%20capital\%20del\%20edificio\%20constituciona

21. Hernández, C. (20 de septiembre de 2013). El Derecho de defensa adecuada en el sistema penal acusatorio. Ciencias Juridicas Universidad de Guanajuato, 4. Obtenido de http://www.cienciajuridica.ugto.mx/index.php/CJ/article/view/37/37

22. Lavina, M., Steluta, I., \& Danil, M. (s/f). El Derecho de Defensa. Revista de la Inquisición, 244. Obtenido de 20derecho\%20a\%20la\%20defensa/DialnetEIDerechoDeDefensa-3821722.pdf

23. Matyas, E. (2013). El Derecho de Defensa en la ley 906 de 2004*.sin una actividad defensiva activa y material no hay derecho de defensa real. Revista Republicana, 137,138. Obtenido de file:///C:/Users/Lucy\%20M/Downloads/21 Texto\%20del\%20artículo-738-1-10-20150810.pdf

24. Masabanda Analuiza, G., Aman Llerena, A., Montero Solano, J., \& Javier Analuiza, E. (2019). La evolución del derecho laboral de la mujer. Protección y fomento de la igualdad. IUSTITIA SOCIALIS, 4(7), 64-96. doi:http://dx.doi.org/10.35381/racji.v4i7.355

25. Oré, A. (s.f.). Las garantías Constitucionales del debido proceso en el nuevo código procesal Penal. Obtenido de www.oreguardia.com.pr: https://www.plagios.org/wp-content/uploads/2019/04/Anexo-7.-ArsenioOre\%CC\%81-Guardia-s.f...pdf

26. Organización de Estado Americanos. (22 de Nov. de 1969). Convención Americana Sobre Derechos Humanos. San José, Costa Rica. Obtenido de https://www.oas.org/dil/esp/tratados_B32_Convencion_Americana_sobre_Derechos_Humanos.pdf 
27. Pizarro, M. (diciembre de 2010). La Detención. Aspectos Generales en el Proceso Penal. Obtenido de Unidad de Estudios Defensoria Regional de la Araucania: http://www.biblio.dpp.cl/biblio/DataBank/5460.doc

28. Ramirez, F. (01 de 01 de 2014). Derecho y Cambio Social. Obtenido de El estado Constitucional: un nuevo paradigma democrático, a propósito de su incidencia en la protección de los Derechos fundamentales: file:///C:/Users/Lucy\%20M/Documents/Downloads/DialnetElEstadoConstitucionalUnNuevoParadigmaDemocraticoA-5472772.pdf

29. Salazar, A., \& Montero, D. (s.f.). Derecho de defensa en la jurisprudencia de la corte interamericana de derechos humanos. Obtenido de http://ddhhyjusticia.org/images/PDF/Documentos/AnalisisEnProfundidad/Derecho _A_La_Defensa_En_La_Jurisprudencia_De_La_CIDH.pdf

30.Sorza , F. (S/F). La detención preventiva en Colombia frente al principio de libertad en los derechos humanos. RAI- Revista Análisis Internacionál, 47. Recuperado el 17 de Diciembre de 2019, de https://revistas.utadeo.edu.co/index.php/RAl/article/view/1078/1122

31. Vaca, R. (s/f). Inconstitucionalidad de la Detención investigativa. Obtenido de www.analisisjuridico.com:

http://www.analisisjuridico.com/publicaciones/articulos/inconstitucionalidad-de-ladetencion-investigativa/ 